\title{
The influence of personality traits on adolescent alcohol consumption trends
}

\author{
Lect. Univ. dr. Mihaela Luminița Sandu \\ “Ovidius" University of Constanta, Romania \\ mihaela_naidin@yahoo.com
}

Prof. univ. dr. habil. Mihaela Rus

“Ovidius" University of Constanta, Romania

psiholog_m@yahoo.com

\section{Lect. univ. dr. Ciprian Vasile Rus}

“Ovidius" University of Constanta, Romania

\begin{abstract}
Adolescence is assessed differently is being called the golden age, ungrateful, great elanuri, drama, crisis, anxiety, insecurity, social integration. Gradually, mental development, especially the intellect is mature in relation to social and cultural make it more accountable. It dominates the living new experiences and tend to self assertion expressions of disdain for the family because the teenager begins to believe that it is in adulthood. Alcohol use in adolescents, personality traits and the factors that determine consumption (psychological, hereditary and environmental, social and environmental), represented in particular by the groups entourage who are trained in adolescents, the subject of this research.
\end{abstract}

Keywords. influence, drug, personality

\section{Introduction}

Adolescence is considered the most beautiful period of life, a period in which the body goes through a series of rapid changes, people begin to form social relations and the need for independence, freedom and belonging to the group manifests itself more clearly than in any other period. of life. In this context, young people come under parental guardianship and try to discover their own personality, their own ideals, although most of the times, their ability to make the best decisions is under-developed.

The reasons why young people use alcohol and drugs are different from their age-specific curiosity, the desire to be part of a socially valued group, the pressure of the group of friends, family models or simply the pleasure of consuming these substances. Thus, the consumption of acool during this period may affect the cognitive development process, the learning process as well as the school performance. 


\section{Research methodology}

Starting from the objective of the research, to investigate the personality traits that predispose to alcohol consumption, we try to demonstrate the existence of a negative correlation between the degree of satisfaction and the tendency towards the consumption of alcohol and the existence of certain personality traits that predispose to alcohol abuse.

The research was conducted on a sample of 50 teenagers. Depending on the biological gender variable, the sample consists of 29 (58\%) male subjects and 21 (42\%) female subjects. (Figure 1).

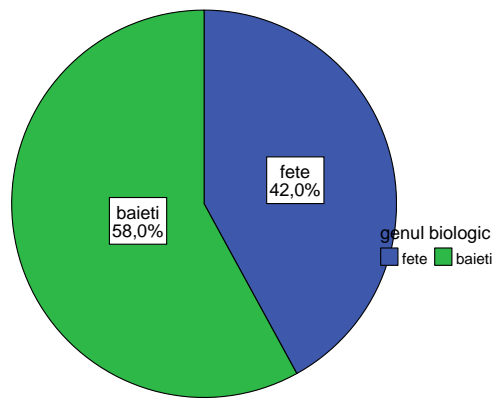

Figure 1 - Structure diagram for the gender variable

A number of 3 research instruments were administered:

- the questionnaire on measuring the degree of satisfaction with one's own person vis-à-vis the social situation (for measuring the degree of satisfaction with one's own person, identifying and understanding some personal factors of failure and understanding of more effective strategies of action);

- the questionnaire regarding the determination of the level of alcohol dependence;

- personality test elaborated by N. Mitrofan (aims to establish the dominant note of the personality of human individuals from the point of view of introversion and extroversion).

\section{Centralization and data analysis}

The scores obtained in the satisfaction questionnaire ranged from 10 to 34 points, their interpretation being achieved by reporting the results on the standard grid as follows: in the sample we observed the existence of two categories according to the results obtained in the satisfaction questionnaire: 10 subjects who they achieved a score of between 10 and 25 points, which means that they are very demanding of themselves, aiming for perfection.

The other 40 subjects obtained results, in the satisfaction questionnaire, between 26 and 34 points, scores denoting people very satisfied with themselves, with great confidence in their abilities, showing security and altruism in relation to the others. 
It is noted that most of the subjects in the sample replied that they believe that they are not normal alcohol users, that is, they think they are drinking more than normal.

It is noted that most of the subjects replied that they believe that their close relatives are not worried about their alcohol consumption, as they do not have the guilt that they are due to the consumption. Alcohol users have a lower passive dependence than non-consumers. Adolescents consume alcohol from the desire to impress others, alcohol being viewed as exciting and challenging. These, to be noted, resort to terrorist and nonconformist behaviors. People who need to be impressed are generally part of the group of friends. The role of parents as well as their relatives is very important in the relationship with adolescents, to keep the communication channels open and to make them aware when consuming alcohol.

In the analyzed group, $25 \%$ of the respondents stated that, when they consume alcohol, they communicate more easily with other people, $10 \%$ do not want to create a separate opinion from the rest of the group. From this it appears that the young man tends to consume alcohol at the pressure of the group. There are people who are convinced that, if those around them are alcohol users, making others represent a sign of integration in the group, of recognition by their peers.

The large number of subjects who consume alcohol for these reasons again demonstrates, if necessary, how much pressure the group has in which young people spend most of their time.If we add to these answers the percentage of $18 \%$ of the subjects who say that drinking alcohol is an integral part of festive occasions (they do not get bored at parties, which proves their high degree of sociability, which could also be stimulated by alcohol consumption), we have a more complete picture of this phenomenon.

However, adolescents (88\%) are convinced that they can stop drinking when they want.

It is noted that most subjects (92\%) responded that they had never been treated for alcoholrelated disorders, which demonstrates the tendency of adolescents to minimize the consequences of alcohol use on all levels.

More than three quarters of the sample stated that they had no problems because they used to drink alcohol. This sends us to the thought that adolescents attribute the causes of problems that have arisen in their lives to factors other than alcohol.

In the studied group $30 \%$ of the subjects heard clarified that they chose to consume alcohol because, the consumption contributes to the good mood and removes stress, and 13\% motivates their consumption by the fact that they like the taste of alcoholic beverages.13\% consume alcohol to reward themselves after an accomplishment.All of these reasons are pretexts to get out of everyday life, to feel good with others.

The rural environment is an environment par excellence collectivist, where children are embraced more, are treated with more tenderness but have less freedom and autonomy compared to 
those from individualistic environments., Where families are warmer than children but manifest a higher control over them.

In the case of urban subjects, the proportion of consumption with friends and colleagues is maintained at a high level ( $44 \%$ and $36 \%$ respectively), but solitary consumption (20\%) appears, which shows a lower desire to adhere to the norms of a group, as and a need to solve everyday problems through the use of alcohol. In the case of respondents from rural areas, unlike those from urban areas, there is a quite high proportion of alcohol consumption with the family (24\%).

From the answers of the adolescents it was found that they consume alcohol on average around the age of 13-14 years in the urban area and 15-16 years in the rural area. The problem of accessibility of alcohol consumption is raised again.

The access to alcoholic beverages is greater for urban adolescents and family control is less intense.

Young people have greater freedom in choosing the behaviors they adopt, the consumption of alcohol at the age of 13 may be hidden from the family, but known by the group of elderly people, which is generally the initial place in which the consumption behavior takes place.

The study participants stated that they never asked anyone for help due to excessive alcohol use, again denying the potential disastrous effects of alcohol use. Respondents also responded that they had not been deprived of the freedom to do anything from the part of those around them, due to the alcohol consumption in $82 \%$ of the investigated sample.

In order to establish a relation between the degree of satisfaction with one's own vis-à-vis the social situation and the level of alcohol dependence, we made the cloud diagram of points to see if there is covariance between the two variables.

From the analysis of the point cloud diagram, a well-determined covariance for the two evaluated phenomena does not result; On the contrary, there are two directions of a covariance, which correspond to the responses given by adolescents to these two evaluation tests: there is a group of adolescents that proves the existence of a positive covariance between the two phenomena, and another less numerous group that meets a positive covariance between these phenomena.

\section{Conclusions}

It can be concluded that the first hypothesis is only partially confirmed: the negative correlation between the degree of satisfaction with one's person and the level of alcohol dependence is only found in some of the adolescents of the studied sample, the others giving answers that prove a positive covariance between the two phenomena. (it was shown to them that the high degree of satisfaction with their own person does not reduce the consumption of alcohol, which makes us believe 
that adolescents "drink" and for reasons other than dissatisfaction with their own person: an example may be the entourage of the group in which they spend much of their free time).

From the analysis of the answers provided by the respondents it was found that three quarters of the adolescents in the sample state that they prefer the situations and the alert activities and the fast working rhythms. Almost three quarters of the adolescents in the study sample state that they do not prefer a quiet environment; it can be observed that the questions with the same intention in the test are repeated, having a control questions role. Most adolescents say they do not prefer activities that require a lot of focus and thoroughness, which demonstrates the tendency of superficiality of adolescents. Which may betray a bloody temperament of these adolescents in the sample studied.

The determination of the introversion / extroversion aspect of the personality of the adolescents in the studied sample, highlights the personality traits with a predisposition towards alcohol consumption. Thus, due to the fact that most adolescents are extroverted in personality, we can conclude the following fact: alcohol consumption appears predominantly in adolescents with extroverted personality, which leads to the confirmation of the second hypothesis.

An important conclusion is drawn from the ones stated so far: young people resort to alcohol consumption in the desire to assert their independence, to be part of a group. In adolescence when the young man moves away from the family, the group of friends and his values become benchmarks in forming his personality.

The degree of satisfaction with one's own person in adolescents seems to influence the level of alcohol dependence, so also their tendency and predisposition to consume alcoholic beverages. The high degree of sociability determines the tendency of adolescents to lead a more active life in society and in the circle of friends.

The limitations of this research must also be taken into account, in the sense that young people can consume alcohol for reasons other than those studied. The influence of the family and the media is not to be neglected, but on the other hand a study that includes all the reasons for consumption is almost impossible to achieve. In conclusion, it is necessary to focus on prevention programs from the earliest ages, before experiencing the first alcohol use or any other substance of this kind.

\section{References}

[1] Abraham P.l, Roncov A. L., Cărăuşu C. (2004). Drogurile: aspecte juridice şi psihosociale, Editura Mirton, Timişoara.

[2] Constantinescu D., Manea M., Ene F. (2001). Incursiuni în problematica alcoolismului, Editura Tehnică, Bucureşti;

[3] Munteanu A. (2003). Psihologia copilului şi a adolescentului, Editura Augusta, Timişoara. 
[4] Rus, M., Tasențe, T., Sandu, M. (2019). Study Regarding the Perception on the Personality Traits in Managerial Decision Making, Journal of Danubian Studies and Research, Vol 9, No 2 (2019) 